\title{
DESENVOLVIMENTO DE UM PROTOCOLO PARA ATENDIMENTO DE PACIENTES COM DOR OROFACIAL E DISFUNÇÃO TEMPORO-MANDIBULAR DO CESUMAR
}

Thiago Ferreira LUIZ, Wagner SIMM, Cristiane Maria Montanari FIGUEIRA, Heitor Segantine Busatto PEREIRA

A Disfunção Temporo-Mandibular (DTM) e Dor Orofacial é um problema de origem multifatorial e que para seu diagnóstico, manejo e controle, necessita de uma visão integrada e multidisciplinar dos diversos aspectos relacionados a esta síndrome. A implantação de um protocolo de atendimento permite instrumentalizar os profissionais a realizar a adequada abordagem, baseando-se em critérios validados, para o correto diagnóstico e conduta a ser tomada nestes pacientes. $\mathrm{O}$ CESUMAR conta com profissionais de diversas áreas da saúde como a Odontologia, Medicina, Fisioterapia, Fonoaudiologia e Psicologia, permitindo uma avaliação multidisciplinar do paciente e resultando em uma conduta de tratamento adequada e mais eficaz. Esta integração proporciona a formação de uma equipe de profissionais calibrada, com características específicas que se fazem necessárias para o controle dos sintomas apresentados pelos portadores de DTM, além de gerar, em médio prazo, uma estrutura para o ensino de graduação e de pós-graduação, formadora de mão-de-obra capacitada para a pesquisa e para projetos de extensão. Desta forma este trabalho visa apresentar a seqüência utilizada para se estabelecer um protocolo de atendimento integrando diferentes áreas do conhecimento em ciências da saúde, e a instalação de um serviço de atendimento multidisciplinar para a dor.

Palavras-chaves: Dor Orofacial; Articulação Temporomandíbular; Métodos. 